\title{
Patients' Lived Experience and Injuries Observed during Upper Digestive Endoscopy at KARA Teaching Hospital (Togo)
}

\author{
Oumboma Bouglouga1, Rafiou El-Hadji Yakoubou1 ${ }^{*}$, Laté Mawuli Lawson-Ananissoh2, \\ Aklesso Bagny', Datouda Redah ${ }^{2}$ \\ ${ }^{1}$ Department of Hepatology and Gastroenterology, CHU-KARA, Kara, Togo \\ ${ }^{2}$ Department of Hepatology and Gastroenterology, CHU-CAMPUS, Lomé, Togo \\ Email: *yrafiou@gmail.com
}

How to cite this paper: Bouglouga, O., El-Hadji Yakoubou, R., Lawson-Ananissoh, L.M., Bagny, A. and Redah, D. (2021) Patients' Lived Experience and Injuries Observed during Upper Digestive Endoscopy at KARA Teaching Hospital (Togo). Open Journal of Gastroenterology, 11, 285-294. https://doi.org/10.4236/ojgas.2021.1112028

Received: November 7, 2021

Accepted: December 27, 2021

Published: December 30, 2021

Copyright $\odot 2021$ by author(s) and Scientific Research Publishing Inc. This work is licensed under the Creative Commons Attribution International License (CC BY 4.0).

http://creativecommons.org/licenses/by/4.0/

(c) (i) Open Access

\begin{abstract}
Background: Endoscopy remains the most performant medical exam exploring the upper digestive tract; but depending on patients, its tolerance is variable. Objective: This study aimed at describing the experience and evaluating the tolerance, acceptability and injuries observed during upper gastrointestinal endoscopy. Methods: This is a prospective and descriptive study carried out from April to July 2017 in the digestive endoscopy unit of the Kara teaching hospital (Togo). The gastroscopy was performed by the same operator (Hepatogastroenteroloogist). The premedication was done with direct intravenous injection of $10 \mathrm{mg}$ of Metoclopramide hydrochloride and viscous Lidocaine oral gel. Previously, essential information about the examination course was given to patients after obtaining their verbal consent. Patients' impressions of the experience, tolerance and acceptability were collected on a survey sheet, before and after the examination. Results: One hundred and eleven patients were included, 62 women and 49 men. The average age was 45.9 years ( 15 - 88 years), and the sex ratio (F/M) was 1.2. Most of the patients (89.2\%) were experiencing the gastroscopy for the first time, and the main reason was epigastralgia in $55 \%$. The examination duration was good at $88.3 \%$ and tolerance was good at $72.1 \%$. Tingling, irritation, pain or sore throat feelings were noted in $13.5 \%$. Patients agreeing to make an ulterior UDE if necessary were up to $92.8 \%$. Observed injuries were dominated by antral erythematous gastropathy (28.8\%). Conclusion: UDE is well tolerated among our patients and its acceptability is high. Injuries are dominated by inflammatory pathologies of the stomach in our population.
\end{abstract}

\section{Keywords}

Upper Digestive Endoscopy, Experience, Tolerance, Acceptability, Injuries, 
Togo

\section{Introduction}

Upper digestive endoscopy (UDE) remains the most efficient examination, to explore the upper digestive tract, for both diagnostic and therapeutic [1]. But its unpleasantness is sometimes reported by patients. Its tolerance, experience and acceptability may be poor and, in some cases, make it laborious or impossible to complete. However, the tolerance of UDE remains variable among patients, and previous studies have shown that several factors may be associated with better acceptability of UDE [2] [3]. UDE is performed most of the time without anesthesia, especially in sub-Saharan Africa, due to the lack of anesthesia specialists. In Togo, there is no precedent study describing the tolerance and acceptability of this examination in patients. Our study aims at describing the experience, tolerance and acceptability of UDE among our patients, and then highlighting the pathologies observed.

\section{Methods}

It was a prospective and descriptive study, in the digestive endoscopy unit of the Kara teaching hospital (Togo). It was based on an anonymous questionnaire, and took place from April to July 2017. Patients aged 15 years and over (hospitalized or outpatients), come for UDE during the study period were included, after obtaining their oral consent (which was mentioned on the survey sheet). The material used for endoscopy performance was an Olympus brand video endoscope with axial vision, equipped with a cold light source, a screen making it possible to visualize the different stages of the endoscopic examination and the pathological aspects observed in real time. Examination was performed by the same doctor (specialist in hepatology and gastroenterology). The material disinfection after use was carried out, according to the manual disinfection protocol, recommended by the French Society of Digestive Endoscopy (SFED); placing the endoscope and its accessories in a Hexanios solution, and brushing accessories. Sterilization was carried out in a $2 \%$ solution of Steranios (glutaraldehyde). The patient should be fasting at least six hours before the exam. The premedication was done with direct intravenous injection of $10 \mathrm{mg}$ of Metoclopramide hydrochloride and viscous Lidocaine oral gel. Before beginning the examination, once the patient is on the examination table, the doctor and/or his assistant reassure and give the patient useful information on the importance and progress of the examination. The patient's questionnaire included items relating to: socio-demographic data (age, sex, marital status, level of education, profession), knowledge or information obtained on UDE before arrival in the center, experience for patients who have already experienced it and the experience description of this examination (painful, painless, unpleasant). The exam lasted from 
three to five minutes. During the endoscopy, the monitor was placed above the patient's head, with an approximate distance of 60 centimeters. Encouragement messages and advices to focus on breathing were given to him. The doctor and his assistant assessed the tolerance by observing the patient's facial expressions and gestures. Tolerance was described as very poor when the patient tried to remove the endoscope with his hand, preventing the gesture from being performed after two attempts. Bad when the patient exhibited body agitation without compromising the examination processing. It was rated as good if the patient remained calm during the course of the exam. At the end of the session, the second part of the questionnaire, relating to the experience of the examination, was completed according to the answers given by the patient. The last part of the questionnaire dealt with the acceptability, which was judged on the patient's willingness or not to repeat the same examination using the same procedure if a subsequent request was made by the attending physician. Three answers were possible (yes, no, don't know). The Epi-Info 6 software was used for data processing and analysis. The Chi2 test was used to compare percentages and Fischer's test when a calculated count was less than 5 .

\section{Results}

Our study has included 111 patients. The average age was 45.9 years (from 15 to $88)$, including 49 men (44.1\%) and 62 women (55.9\%) with a sex ratio (F/M) of 1 , 2. The most represented group was $40-50$ years old $(27.9 \%)(\mathrm{n}=32)$. Socio-demographic characteristics of the population are shown in Table 1. According to the education level, patients with high school education were the most represented $(39.6 \%)(n=44)$, followed by university level $(26.2 \%)(n=29)$. Estimated 89.2\% $(\mathrm{n}=99)$ of patients were experiencing their first UDE. Among the $10.8 \%$ of patients who had already performed this test, $8.1 \%(n=9)$ did it only once and $0.9 \%(\mathrm{n}=1)$ twice. The UDE was mainly indicated to explore epigastralgia (59.4\%), to look for oesophageal varicose veins (15.3\%) and to explore an ulcer syndrome (Table 2). Medical information concerning the examination was given to patients in $37.8 \%(\mathrm{n}=42)$; through the endoscopist, or his assistant (22.5\%). The endoscopy was asked by a doctor in $84.7 \%$, and a medical assistant in $9.9 \%$. Information about the examination process was given to patients just before its performance in $97.3 \%(n=108)$. Most of the patients found the welcome good in $94.74 \%(\mathrm{n}=108)$ and acceptable in $3.6 \%$. The majority of patients, 97.3\% ( $\mathrm{n}=108)$ thought that the achievement of UDE was important to resolve their health problem. Only $25.2 \%(n=28)$ knew someone who had once performed the exam, and $14.4 \%(\mathrm{n}=16)$ told them that it was unpleasant and/or painful. The examination was rated unpleasant in $16.2 \%(\mathrm{n}=18)$, frightening and worrying in $8.1 \%(n=9)$. Most of the patients $(72.1 \%)$ had no impression of the exam before it was performed. Eighty-five patients (76.6\%) said they were confident before the exam. At the end of the examination, $40.5 \%$ of the patients $(\mathrm{n}=45)$ found it painful and $27.9 \%$ unpleasant (Table 3$)$. The exam room had 
Table 1. Sociodemographic characteristics of patients.

\begin{tabular}{|c|c|c|}
\hline & $\mathbf{n}$ & $\%$ \\
\hline \multicolumn{3}{|l|}{ Gender } \\
\hline Female & 62 & 55.9 \\
\hline Male & 49 & 44.1 \\
\hline Average age & $45.9(15-85)$ & \\
\hline \multicolumn{3}{|l|}{ Marital status } \\
\hline Married & 71 & 64 \\
\hline Single & 29 & 26.1 \\
\hline Widow(er) & 9 & 8.1 \\
\hline Divorced & 2 & 1.8 \\
\hline \multicolumn{3}{|l|}{ Level of study } \\
\hline Unschooled & 18 & 16.2 \\
\hline Primary school & 20 & 18 \\
\hline Secondary school & 44 & 39.6 \\
\hline University & 29 & 26.6 \\
\hline \multicolumn{3}{|l|}{ Jobs } \\
\hline Officials & 27 & 24.3 \\
\hline Housewife & 22 & 19.8 \\
\hline Trader & 18 & 16.2 \\
\hline Student & 16 & 14.4 \\
\hline Farmer & 10 & 9 \\
\hline Artisan & 9 & 8.1 \\
\hline Retired & 5 & 4.5 \\
\hline Religious & 1 & 0.9 \\
\hline Unemployed & 3 & 2.7 \\
\hline
\end{tabular}

Table 2. Reasons motivating the upper digestive endoscopy.

\begin{tabular}{ccc}
\hline & $\mathbf{n}$ & $\%$ \\
\hline Epigastralgia & 66 & 59.4 \\
Looking for esophageal varicose veins & 17 & 15.3 \\
Ulcer syndrome & 13 & 10.8 \\
Upper gastrointestinal bleeding & 3 & 2.7 \\
Gastroesophageal reflux & 5 & 4.5 \\
Abdominal pain & 4 & 3.6 \\
Chest pain & 2 & 1.8 \\
Etiological research of severe anemia & 1 & 0.9 \\
\hline
\end{tabular}

Table 3. Patients' impressions after performing the UDE.

\begin{tabular}{ccc}
\hline & n & $\%$ \\
\hline Painful & 45 & 40.5 \\
Painless & 29 & 26.1 \\
A bit unpleasant & 31 & 27.9 \\
Unpleasant & 4 & 3.6 \\
A bit painful and a bit unpleasant & 6 & 5.4 \\
\hline
\end{tabular}


no effect on patients in $49.5 \%$ and $36 \%$ of them rated the exam room clean, well equipped, well-appointed and comfortable. The room also had no effect on exam processing in $87.4 \%$ of cases. A minority of patients $(5.4 \%)$ said the exam room was too cold. The exam duration was considered good in $88.3 \%(\mathrm{n}=98)$ and long in $10.8 \%$.

After examination, $46.8 \%$ of patients reported feeling nothing, and similarly, $46.8 \%$ reported relief. Tingling, irritation or sore throat feelings were reported in $13.5 \%(n=15)$. No complications were observed. The acceptability of a subsequent UDE under the same conditions was noted in $92.8 \%(n=103)$. At the end of the examination, $39.6 \%$ of patients expressed their thanks to the medical team and $9.9 \%$ had encouraged them to continue working the same way. The patient cooperation's degree was rated acceptable in $76.6 \%(n=85)$ and good in $23.4 \%$ $(\mathrm{n}=26)$. The endoscopy performance was normal in $87.38 \%$ (97 patients), then a bit laborious in $12.61 \%$ (14 patients). The most found pathology was antral erythematous gastropathy $(28.8 \%)$ (Table 4$)$.

\section{Discussion}

This study, focusing on the experience, tolerance and acceptability of UDE among patients, is the first one in Togo. Responding to the post-endoscopic questionnaire immediately, while some patients were still feeling emotional, could constitute a bias. Likewise, the question relating to the acceptability of UDE could vary if the investigation was carried out a few days later. On another side, the fact that the questionnaire was not self-administered (but administered by someone) could influence the patients' answers as they don't want to compromise the medical team. The female predominance in our study population is also reported by other African authors [4] [5] [6]. This female predominance could be explained by the great attention that women pay to their health. Male predominance cases have been reported by Soro et al. in Ivory coast [7]. Our patients'

Table 4. Patients according to pathologies observed at the UDE.

\begin{tabular}{ccc}
\hline Pathology & $\mathbf{n}$ & $\%$ \\
\hline Erythematous antral gastropathy & 32 & 28.8 \\
Duodenogastric bile reflux & 20 & 18 \\
Erythematous fundic gastropathy & 13 & 11.7 \\
Congestive pangastropathy & 13 & 11.7 \\
Erythematous pangastropathy & 11 & 9.9 \\
Bulbite and erythematous bulboduodenitis & 4 & 3.6 \\
Uncomplicated hiatus hernia & 2 & 1.8 \\
Peptic ulcer & 1 & 0.9 \\
Peptic esophagitis & 1 & 0.9 \\
Mycotic esophagitis & 1 & 0.9 \\
Normal & 13 & 11.71 \\
\hline
\end{tabular}


average age was 45.9 years (ranging from 15 to 88 ) and was higher than the one reported by Sombié et al. in Burkina-Faso [4]. Officials were the most represented, probably due to the health insurance for officials granted in Togo. Our patients were mostly educated as is the case in the African literature [4] [5]. Only $37.8 \%$ of patients had medical information about the procedure before arriving in the examination room and in $22.5 \%$, it was given by the endoscopist assistant. This is due to the lack of gastroenterologists; Togo has only eight gastroenterologists, including only one working in the northern part of the country. Once on the examination table, the majority of patients (97.3\%) had received the necessary information on the course of the UDE before its realization against $30.8 \%$ according to Sombie et al., thus explaining the good tolerance of UDE observed in our study. However, information given to patients was verbal, whereas the French Society of Endoscopy Digestive recommends the use of an information sheet which should be commented on and given to patients during consultation [8]. This information should be given to patients during a pre-examination consultation, preferably the day before as this could improve safety and acceptability [9] [10]. Unfortunately, this was not the case at the Kara teaching hospital where we work in a rural hospital environment with a critical deficit of paramedical personnel. Indeed, the tolerance of EDH may be assessed differently by patients or doctors [3] [11], the latter being able to minimize the discomfort caused by the examination. Thus, the good tolerance of UDE in our survey was $72.1 \%$ and approached the results of Sombié et al. in Burkina-Faso [4], Ibara et al. in Congo [12], Amourreti in France [13] and Ndjitoyap N'dam et al. in Cameroon [6] who reported a good tolerance rate of $84.6 \%, 85.7 \%, 86 \%$ and $86.6 \%$ respectively. Most of our patients (89.2\%) were at their first realization of the UDE and this fact had no influence on the tolerance or not of the exam. The key element of good safety was the exam duration, and $88.3 \%(n=98)$ found the duration good (less than 5 minutes) as was the case in the literature [5] [12]. Likewise, the examination room had no effect on the UDE performing, thus explaining, on the one hand, the good tolerance of the examination by the patients. Tingling, irritation, or sore throat sensation was reported in $13.5 \%$. These different feelings described in the throat were noted in $40 \%$ according to Sombié et al. [4] and in $44 \%$ according to Sehonou et al. [5]. The patient's acceptability to repeat the exam under the same conditions was $92.8 \%$. This result is stackable on those of African authors [5] [6], with rates ranging from $91 \%$ to $97.7 \%$. This excellent acceptability of UDE in our context could be explained by the good quality of the reception (96.4\%), information given to patients just before the examination by the doctor or his assistant (97.3\%); the exam short duration ( $88.3 \%$ good duration); the absence of complications, and finally the good behavior of the digestive endoscopy team because at the end of the examination $39.6 \%$ of the patients wanted to thank us for the work done. The examination performance happened in $97 \%$ without any incident with patient cooperation judged acceptable in 76.6\%. However, this degree of cooperation could be improved if the examina- 
tion was performed under anesthesia. The predominance of antral erythematous gastropathy as the main pathology observed was also reported by Lawson-Ananisso et al. [14].

\section{Conclusion}

The majority of our patients have well experienced the UDE as evidenced by the absence of noted complications. Tolerance and acceptability of the exam are good in our study population and a large number of patients are willing to repeat the exam under the same conditions. The level of cooperation was acceptable and this level could be improved if the examination was performed under anesthesia.

\section{Authors' Contributions}

Oumboma Bouglouga is the initiator and coordinator of the drafting of the manuscript in its final version. Rafiou El-Hadji Yakoubou participated in data collection, bibliographic research and drafting of the manuscript. Aklesso Bagny, Laté Mawuli Lawson-Ananissoh and Redah Datouda participated in the bibliographic research, the reading and correction of the manuscript in its final version.

\section{Conflicts of Interest}

The authors declare that they have no competing interests.

\section{References}

[1] Dooley, C.P., Larson, A.W., Stace, N.H., Renner, I.G., Valenzuela, J.E., Eliasoph, J., Colletti, P.M., Halls, J.M. and Weiner, J.M. (1984) Double-Contrast Barium Meal and Upper Gastrointestinal Endoscopy. Annals of Internal Medicine, 101, 538-545. https://doi.org/10.7326/0003-4819-101-4-538

[2] Hoare, A.M. and Hawkins, C.F. (1979) Upper Gastrointestinal Endoscopy with and without Sedation: Patient's Opinions. British Medical Journal, 2, 20. https://doi.org/10.1136/bmj.2.6026.20

[3] Schutz, S.M., Lee, J.G., Schmitt, C.M. and Baillie, J. (1994) Patient Satisfaction with Conscious Sedation for Endoscopy. Gastrointestinal Endoscopy, 40, 119-120. https://doi.org/10.1016/S0016-5107(94)70038-9

[4] Sombié, R., Guingané, A., Tiendrébéogo, A., Gansané, Z. and Bougouma, A. (2016) Évaluation de la tolérance et de l'acceptabilité de l'endoscopie digestive haute chez 350 patients. Journal Africain d Hépato-Gastroentérologie, 10, 6-9. https://doi.org/10.1007/s12157-015-0630-8

[5] Sehonou, J., Kodjoh, N. and Addra, B. (2005) Tolérance et acceptabilité de l'oesogastroduodénoscopie sans sédation à l'hôpital d'instruction des armées de Cotonou. Acta Endoscopica, 35, 493-498. https://doi.org/10.1007/BF03003904

[6] Ndjitoyap N'dam EC, Njoya O, Tzeuton Christian. (1998) Tolérance et acceptabilité de l'endoscopie digestive haute. Etude analyse prospective de 530 examens. Acta Endoscopica, 28, 296.

[7] Soro, D., Ouattara, M.-J.L.K.A., Koné, S., Kouassi. A.M., Diakité, M. and Camara, 
B.-M. (2013) Tolérance et acceptabilité de la gastroscopie chez l'adulte en Côte d'Ivoire à propos de 300 cas. Mali Médical, 28, 29-31.

[8] Société Française d'Endoscopie Digestive (SFED) Société Nationale Française de Gastro-entérologie (SNFGE) (1998) Informations médicales avant réalisation d'une gastroscopie diagnostique. Acta Endoscopica, 28, 311.

[9] Camille, C.-M., de Decker, L., Chevalet, P., Berlioz-Thibal, M., Aoudia, V.O. and Berrut, G. (2009) Evaluation de la tolérance des fibroscopies œsogastroduodénales chez les sujets âgés. Annals of Gerontology and Geriatric Research, 2, 161-167.

[10] Balamane, A., Oussalah, A., Bensenane, M., Kaddache, N., Layaïda, K., Gamar, L., Kecili, L., Bounab, N., Belhocine, K., Debzi, N., Baïod, N. and Boucekkine, T. (2008) Impact de l'information du patient avant une endoscopie digestive. Expérience d'un service hospitalo-universitaire. Endoscopy, 40, 122.

https://doi.org/10.1055/s-2008-1066961

[11] Raymond, J.M., Michel, P., Capdenat, E., Beyssac, R., Couzigou, P., Janvier, G., et al. (1996) Conditions de réalisation de l'endoscopie digestive haute en ambulatoire: résultats d'une enquête nationale (1). Gastroentérologie Clinique et Biologique, 20, 564-569.

[12] Ibara, J.R., Okouo, M., Attipo-Ibara, B.I., et al. (1997) Tolérance et acceptabilité de l'endoscopie digestive haute chez le noir Africain. Annals of Clinical Gastroenterology and Hepatology, 33, 77.

[13] Amouretti, M. (1991) Evaluation de la satisfaction des malades après une endoscopie digestive haute et ses relations avec les conditions de réalisation de cet examen. Acta Endoscopica, 21, 324-339. https://doi.org/10.1007/BF02968499

[14] Lawson-Ananissoh, L.M., Bouglouga, O., El-Hadji Yakoubou, R., Bagny, A., Kaaga, L. and Redah, D. (2014) La fibroscopie digestive haute chez le sujet noir africain âgé. Journal de la Recherche Scientifique de IUniversité de Lomé (Togo), Série D, 16, 267-274. 


\section{Abbreviation}

UDE: Upper digestive endoscopy.

\section{Annex}

Survey sheet concerning the experience of patients during upper digestive endoscopy at the teaching hospital of kara

1) Do you agree to participate in this survey? YES _ NO NO

\section{A) Pre-endoscopy questionnaire}

2) Gender: Male___ Female__ Transgender

3) Age: years

4) Marital situation: Single___ Maried__ Divorced Widower

5) Job:

6) Study level: Primaire___ Secondaire__ Universitaire

7) Reasons motivating this upper digestive endoscopy:

8) Who has asked you to do the upper digestive endoscopy?

Doctor__ Medical assistant___ Nurse__ Midwife__ Another

9) Have you been informed about the endoscopy exam processing? YES $\mathrm{NO}$

10) What are your impressions concerning this exam?

11) Do you think this exam is important to solve your health problem? YES__ NO

12) Did you ever realize this endoscopic exam? YES $\mathrm{NO}$

If YES, how many times?

13) Do you know someone who have almost realized this exam? YES $\mathrm{NO}$

If YES, what did he/she tell you about this exam?

14) How do you feel before starting this exam?

Confident Anxious Stressed Depressed

\section{B) After endoscopy questionnaire}

15) After the exam, what are your impression about the upper digestive endoscopy?

Painless A bit painful Painful Very painful

A bit unpleasant Unpleasant Very unpleasant

16) What are your impressions concerning the exam room?

Did the exam room have an impact in the exam processing? YES $\mathrm{NO}$

If YES, which one?

17) How did you appreciate the exam duration?

Good Long___ Very long

18) Did the endoscopiste and his helper give you necessary informations about the exam processing? YES $\mathrm{NO}$

19) What can you say about the welcome you received? 
Good___ Acceptable___ Bad___ Nothing to say

20) What do you feel after the exam?

21) Would you agree to make it again one day?

YES__ NO__ DON'T KNOW

22) Which particular thing do you have to tell us?

\section{C) Endoscopist point of view}

23) What was the patient's level of cooperation?

Bad___ Acceptable__ Good_

24) How do you appreciate the process of the exam with this patient? Normal__ A bit laborious___ Laborious 